\title{
Confronting two biomolecular techniques to detect NRF2 gene polymorphism biomarkers
}

Pieranna Chiarella*,1, Renata Sisto ${ }^{1}$ \& Ario de Marco ${ }^{2}$

${ }^{1}$ INAIL Research - Department of Occupational \& Environmental Medicine, Epidemiology \& Hygiene. Via Fontana Candida 1 00078 Monte Porzio Catone (RM), Italy

${ }^{2}$ Laboratory for Environmental \& Life Sciences - University of Nova Gorica, Vipavska 13, S-5000 Nova Gorica, Slovenia

*Author for correspondence: p.chiarella@inail.it

\begin{abstract}
Aim: Gene polymorphism biomarkers identify individual susceptibility to environmental and occupational hazards. The conventional approach considers polymerase chain reaction (PCR) followed by restriction fragment length polymorphism analysis (RFLP), a reliable but expensive and time-consuming two-step procedure. Therefore we evaluated the simpler method confronting two-pair primers (CTPP)-PCR for its robustness and applicability to epidemiologic studies. Materials \& methods: We compared CTPP-PCR and PCR-RFLP techniques to detect two NRF2 polymorphisms in a set of biological samples. Results: CTPP-PCR produced contradictory results and required the orthogonal technique for confirming the data. Conclusion: In contrast to PCR-RFLP, CTPP-PCR of NRF2 polymorphisms resulted in ambiguous genotyping which strongly jeopardized heterozygosis classification. The necessity of long optimization and control procedures nullified the potential advantages of CTPP-PCR in terms of costs and time.
\end{abstract}

Lay abstract: Confronting two-pair primers-polymerase chain reaction (CTPP-PCR) is potentially a fast, simple and cost-efficient method for the detection of gene polymorphism biomarkers. This technique was used to genotype two SNPs of NRF2 gene in a set of biological samples but resulted in ambiguous results. Therefore, it was necessary to validate the CTPP-PCR genotyping data with the orthogonal technique PCR-RFLP. Since reproducibility is a critical issue in both biomedical research and diagnostics, we advise pairing CTPP-PCR with control methods and evaluating whether the overall package is still convenient for massive genetic screening.

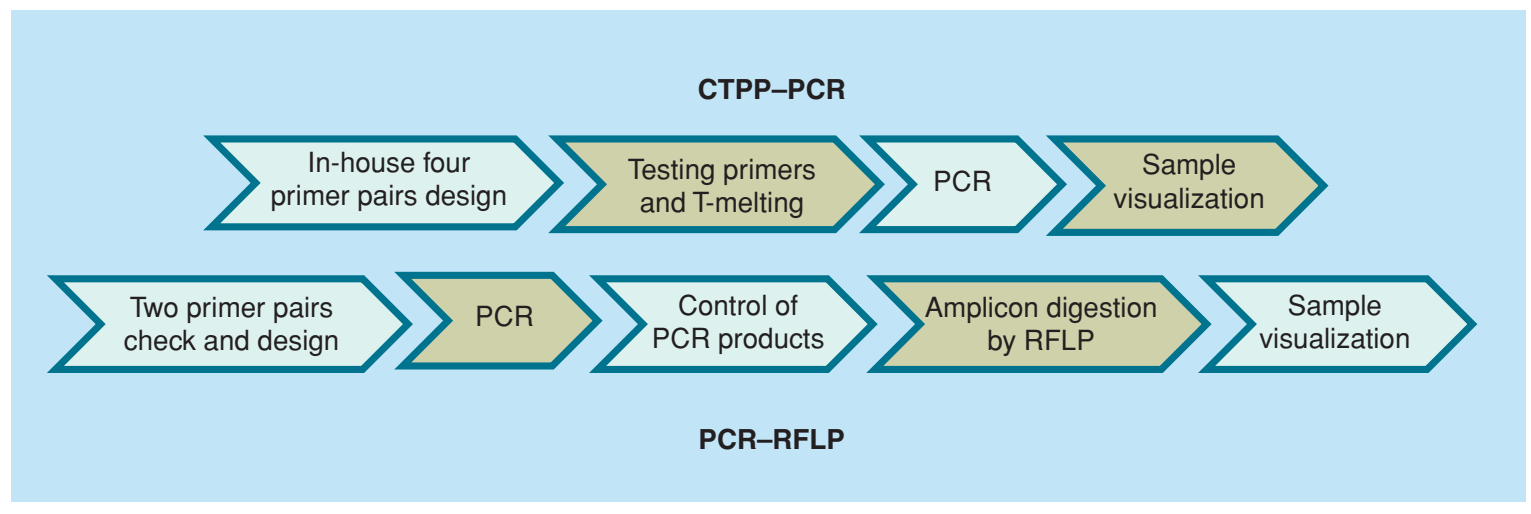

First draft submitted: 30 July 2018; Accepted for publication: 29 October 2018; Published online:

11 December 2018

Keywords: biomarker $\bullet$ confronting two-pair primers $\bullet$ gene polymorphism $\bullet$ NRF2 $\bullet$ oxidative stress $\bullet$ PCR $\bullet$ RFLP - susceptibility

Single nucleotide polymorphisms (SNPs) are the most common type of genetic variations in humans and are evaluated as susceptibility biomarkers in studies of exposure to xenobiotics [1]. Individual genetic profiles may 
provide useful indications of susceptibility to toxicants and consequently improve the risk assessment procedures used to ensure health protection in occupational and environmental contexts [2].

Polymerase chain reaction (PCR) followed by restriction fragment length polymorphism (RFLP) still remains the gold standard method to identify SNPs [3] and despite the appearance of high-throughput techniques in the last decade (i.e., denaturing high-performance liquid chromatography, high-resolution melting analysis, $\mathrm{SNaPshot}$, next-generation sequencing) $[4,5]$, it remains the preferred option for genotyping in laboratories that cannot afford expensive instrumentations or have no access to genotyping service. In this two-step process, genes are amplified with a primer pair and afterward the amplicon is digested by specific endonuclease restriction enzymes before final evaluation of the digestion patterns. PCR with confronting two-pair primers (CTPP-PCR) has been developed as a faster, simpler and inexpensive alternative to PCR-RFLP. The original method, conceived by Hamajima and coworkers [6], has been further improved and adapted to an increasing panel of SNPs in the last 15 years [7-10]. The rationale is based on the design of two couples of primers which amplify: the wild-type allele (F1-Forward 1 and R1-Reverse 1); the variant allele (F2-Forward 2 and R2-Reverse 2); and any allele (F1 and R2). In both F2 and R1 sequences the nucleotide located at the $3^{\prime}$ end is modified to allow the amplification of the specific SNP [6]. The PCR reaction results in two or three amplicons of different length, depending on the individual haplotype. F1-R1 and F1-R2 are specific for the homozygous wild-type allele; F1-R2 and F2-R2 are specific for the homozygous variant allele; F1-R1, F2-R2, F1-R2 characterize the heterozygous genotype. Amplicons are visualized on agarose gel by electrophoresis without further steps. However, since two forward and two reverse primers are used simultaneously in the same reaction, competition among oligonucleotides may occur and the stronger affinity of the most specific may result in preventing the other from binding to the template $[11,12]$. This condition might critically jeopardize the final result [13].

Based on previous published data [6-9], we applied CTPP-PCR to the screening of selected SNPs of NRF2 (Gene ID: 4780). This gene is important in the study of individual exposure to toxicants and carcinogens being a key regulator of the cell transcriptional response to oxidative stress [14]. Studies on animal models have shown that NRF2 protects the inner ear against age-related hearing injuries and gentamicin ototoxicity by up-regulating antioxidant enzymes and detoxifying proteins [15]. In a cohort subjected to occupational noise exposure, NRF2 rs6721961 SNP accounted for the increase of susceptibility to noise-induced hearing loss caused by free radical production [16]. Other studies showed that NRF2 SNPs of the promoter region have been associated with vitiligo risk in the Chinese population $[17,18]$. This genetic disorder is often under-estimated even though the severity of epidermal lesions tends to worsen when individuals are occupationally exposed to chemical and physical stressful agents.

At least 17 NRF2 SNPs have been identified for their association with disease risk and evaluated for their effects on gene expression and function [14]. In particular, three polymorphisms (namely rs6721961, rs35652124 and rs6706649) located in the $5^{\prime}$ promoter region of NRF2 seem to be associated to specific susceptibilities and were proposed as biomarkers [16-20].

Since unambiguous and reproducible results are essential requests in diagnostics, we wanted to compare the robustness and reliability of CTPP-PCR with PCR-RFLP for the characterization of two of these polymorphisms, NRF2 rs6721961 (-617 C/A) and NRF2 rs35652124 (-653 A/G), with the idea to extend its application to the study of larger populations of individuals exposed to risk factors.

\section{Materials \& methods}

Human participants to the study

16 Caucasian individuals, belonging to our Institute, were enrolled on the basis of their personal agreement as volunteers to participate to the study. A second group of eight volunteers was enrolled from a biomonitoring campaign directed to workers employed in a ship construction company in Tuscany (Italy). Of these, four were ship painters and the others were administrative personnel. All individuals were eligible and agreed to the methodological study after giving their informed consent. Inclusion criteria were age 30-55 years; participants included both males and females. Data obtained in this study were anonymous and can only be interpreted on a population level. All procedures performed in this study involving human participants (Declaration of Helsinki) were in accordance with the ethical standards of our institutional committee and in accordance with the local ethics committee (USL North-West, Tuscany, July 2017). 


\section{Table 1A. Primer sequences and melting temperatures.}

\begin{tabular}{|lll|}
\hline SNP & Nucleotide sequence & T melting \\
\hline rs6721961 & & \\
\hline F1 & CTCCGTTTGCCTTTGACGAC & $56.6^{\circ} \mathrm{C}$ \\
\hline R1 & GGGGAGATGTGGACAGCG & $58.3^{\circ} \mathrm{C}$ \\
\hline F2 & GCGAACACGAGCTGCCGGA & $6^{\circ} \mathrm{C}$ \\
\hline R2 & CCCTGATTTGGAGTTGCAGAACC & $58.3^{\circ} \mathrm{C}$ \\
\hline rs35652124 & & \\
\hline F1 & GGGGTTCCCGTTTTTCTCCC & $58.5^{\circ} \mathrm{C}$ \\
\hline R1 & GCAGTCACCCTGAACGCCCT & $62.5^{\circ} \mathrm{C}$ \\
\hline F2 & GACACGTGGGAGTTCAGAGGG & $59.6^{\circ} \mathrm{C}$ \\
\hline R2 & CTTTTATCTCACTTTACCGCCCGAG & $57.4^{\circ} \mathrm{C}$ \\
\hline
\end{tabular}

F2 and R1 allele-specific nucleotides at $3^{\prime}$ end are highlighted in bold.

SNP: Single nucleotide polymorphism.

Table 1B. Confronting two-pair primers-polymerase chain reaction and restriction fragment length polymorphism

\section{product length.}

\begin{tabular}{|c|c|c|c|c|}
\hline Genotype & $\begin{array}{l}\text { rs6721961 C/A Product size } \\
\text { (CTPP-PCR) }\end{array}$ & $\begin{array}{l}\text { rs35652124 A/G Product size } \\
\text { (CTPP-PCR) }\end{array}$ & $\begin{array}{l}\text { rs6721961 C/A Product size } \\
\text { (PCR-RFLP) }\end{array}$ & $\begin{array}{l}\text { rs35652124 A/G Product size } \\
\text { (PCR-RFLP) }\end{array}$ \\
\hline Homozygous (wild-type) alleles & $\begin{array}{l}282 \& 113 b p \\
\text { (CC) }\end{array}$ & $\begin{array}{l}318 \& 146 \mathrm{bp} \\
\text { (AA) }\end{array}$ & $191 \& 91 \mathrm{bp}$ & $180 \& 138 \mathrm{bp}$ \\
\hline Heterozygous alleles & $\begin{array}{l}282 \& 205 \& 113 b p \\
\text { (CA) }\end{array}$ & $\begin{array}{l}318,213, \& 146 b p \\
(A G)\end{array}$ & $282 \& 191 \& 91 \mathrm{bp}$ & $318 \& 180 \& 138 b p$ \\
\hline Homozygous (variant) alleles & $\begin{array}{l}282 \& 205 b p \\
\text { (AA) }\end{array}$ & $\begin{array}{l}318 \& 213 b p \\
\text { (AA) }\end{array}$ & $\begin{array}{l}282 \text { bp } \\
\text { (AA) }\end{array}$ & $\begin{array}{l}318 \mathrm{bp} \\
\text { (GG) }\end{array}$ \\
\hline
\end{tabular}

CTPP: Confronting two-pair primer; PCR: Polymerase chain reaction; RFLP: Restriction fragment length polymorphism.

\section{Table 1C. Conditions used for confronting two-pair primers-polymerase chain reaction amplification.}

$$
\text { SNP }
$$

Number of cycles

Hot start

Denaturation

Annealing

Extension

Final extension

End of reaction

SNP: Single nucleotide polymorphism

\begin{tabular}{ll} 
rs6721961 C/A & rs35652124 A/G \\
35 & 35 \\
$95^{\circ} \mathrm{C}, 5 \mathrm{~min}$ & $95^{\circ} \mathrm{C}, 5 \mathrm{~min}$ \\
\hline $95^{\circ} \mathrm{C}, 1 \mathrm{~min}$ & $95^{\circ} \mathrm{C}, 1 \mathrm{~min}$ \\
\hline $58^{\circ} \mathrm{C} / 65^{\circ} \mathrm{C}, 1 \mathrm{~min}$ & $59^{\circ} \mathrm{C} / 66^{\circ} \mathrm{C}, 1 \mathrm{~min}$ \\
\hline $72^{\circ} \mathrm{C}, 1 \mathrm{~min}$ & $72^{\circ} \mathrm{C}, 1 \mathrm{~min}$ \\
$72^{\circ} \mathrm{C}, 5 \mathrm{~min}$ & $72^{\circ} \mathrm{C}, 5 \mathrm{~min}$ \\
$4^{\circ} \mathrm{C}, \infty$ & $4^{\circ} \mathrm{C}, \infty$
\end{tabular}

\section{DNA extraction}

Genomic DNA was isolated from urine exfoliate and blood of the recruited human volunteers. DNA was extracted from urine exfoliate according to the method described previously [21] whereas blood DNA was recovered by using the QiAmp DNA blood mini kit cat. N. 51306 (Qiagen, Germany). Blood was sampled from medical staff with informed consent and according to the INAIL ethical guidelines.

\section{Confronting two-pair primers polymerase chain reaction}

Confronting two-pair primer sequences specific for the -617 C/A and -653 A/G polymorphisms of NRF2 (Table 1A) and experimental conditions were designed according to previous publications [19,22]. Oligonucleotides were checked for correct DNA complementarity by publicly available softwares Kalign and Multalin (www.ebi.ac.uk/Tools/msa/ kalign/; multalin.toulouse.inra.fr/multalin/) and purchased by Metabion GmbH - Dasit Carlo Erba (GermanyItaly).

PCR product details and experimental PCR conditions are summarized in Table 1B and Table 1C, respectively. Since F2 (rs6721961) and R1 (rs35652124) have melting temperature significantly different from the others, 


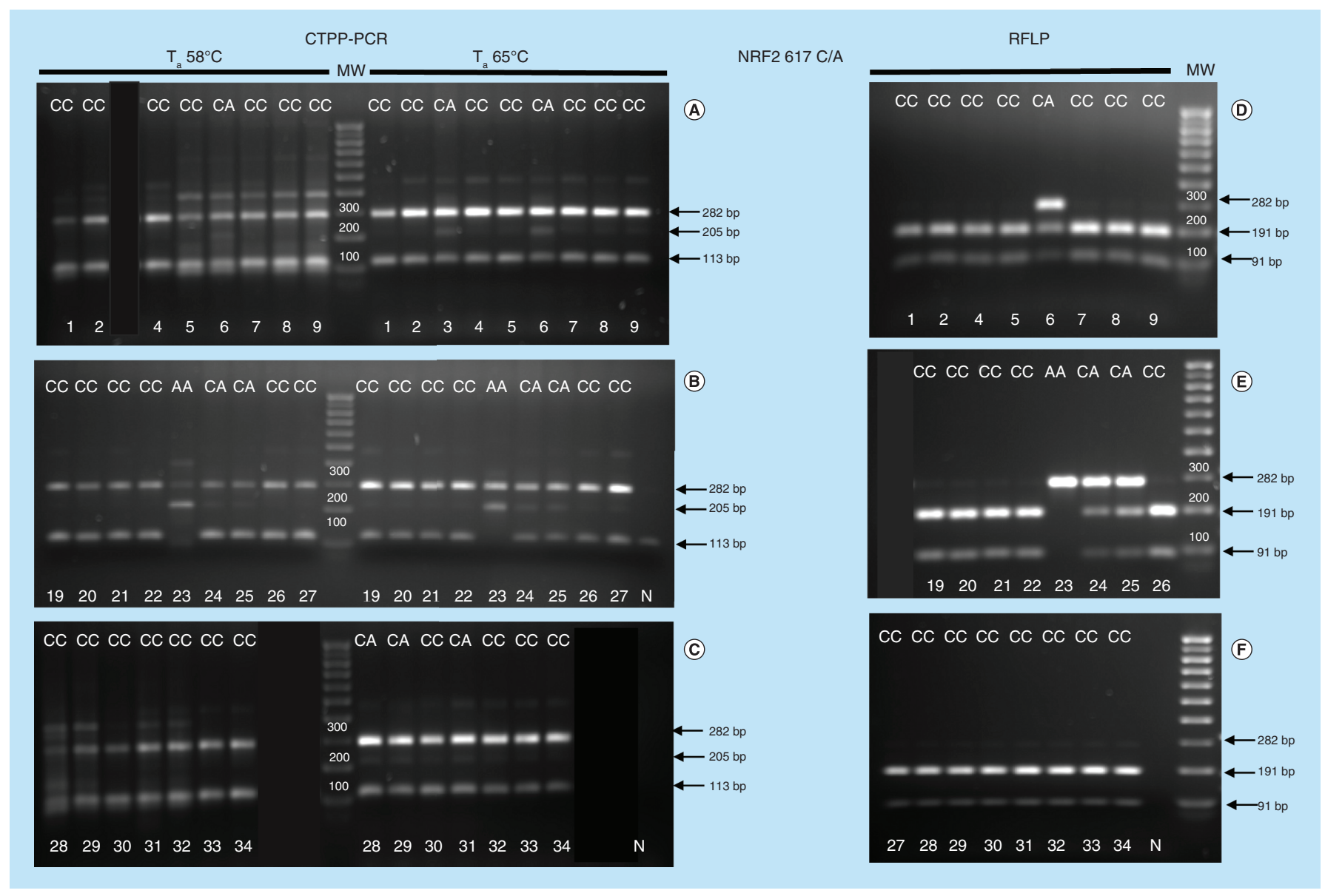

Figure 1. Comparison between CTPP-PCR and RFLP results for NRF2-617C/A SNP. Confronting two-pair primers-polymerase chain reaction of NRF2 rs6721961 (-617 C/A) single nucleotide polymorphism performed at two different $\mathrm{T}_{\mathrm{a}}\left(58^{\circ}-65^{\circ} \mathrm{C}\right)$ using 1 unit/sample of Kapa Hot Start Taq polymerase (A-C). Restriction fragment length polymorphism analysis after amplicon digestion with NgoMIV (D-F). Sample ID and genotype are indicated by numbers and letters at the top and bottom of figures.

CTPP: Confronting two-pair primer; N: Negative control indicates DNA template omission in the polymerase chain reaction; MW: Molecular weights (100 bp up to 1000 bp); RFLP: Restriction fragment length polymorphism; SNP: Single nucleotide polymorphism. The black lanes are irrelevant samples for which the corresponding confronting two-pair primers-polymerase chain reaction was not reported.

CTPP-PCR reactions were performed using the gradient option of the thermocycler (Multigene optimax thermal cycler, Aurogene SRL, Italy) that enables contemporary polymerization reaction at two different annealing temperatures $\left(\mathrm{T}_{\mathrm{a}}\right)$. All PCRs were performed with 1 unit/sample of Kapa Hot Start Taq polymerase, Biosystems Cat. KK1508 (Sigma-Aldrich, MO, USA) except for the PCR shown in Figure 3 where 2.5 units/sample of AmpliTaq Gold polymerase, Applied Biosystems Cat. N8080161 (ThermoFisher Scientific, MA, USA) were used. PCR products were separated on 1.5\% agarose gel Cat. BMR 918100 (Euroclone, MI, Italy) with TBE (Tris, Boric acid, EDTA) buffer and stained with gel red staining solution (Biotium, CA, USA). Gel images were acquired by means of PXi4 image analyzer equipped with the GenSys software (Syngene, MD, USA).

Polymerase chain reaction-restriction fragment length polymorphism

NRF2 -617C/A and NRF2 -653A/G amplicons were obtained using primers F1 and R2 for each SNP, as indicated in Table $1 \mathrm{~A}$ and at the same experimental conditions used in CTPP-PCR and with the same Taq polymerase except for the $\mathrm{T}_{\mathrm{a}}$, which was $62^{\circ} \mathrm{C}$. The expected amplicon size was $282 \mathrm{bp}$ for $N R F 2-617 \mathrm{C} / \mathrm{A}$ and 318 bp for NRF2 -653 A/G (Supplementary Figure 1). Enzymatic digestion of NRF2 -617 C/A amplicon was performed with 7.5 units per sample of NgoMIV restriction enzyme (New England Biolabs, MA, USA; Euroclone), incubated for 90 min at $37^{\circ} \mathrm{C}$ without enzyme inactivation. Enzymatic digestion of NRF2-617 A/G amplicon was performed with 15 Units per sample of BseRI restriction enzyme (New England Biolabs, Euroclone), incubated for 90 min at $37^{\circ} \mathrm{C}$ followed 


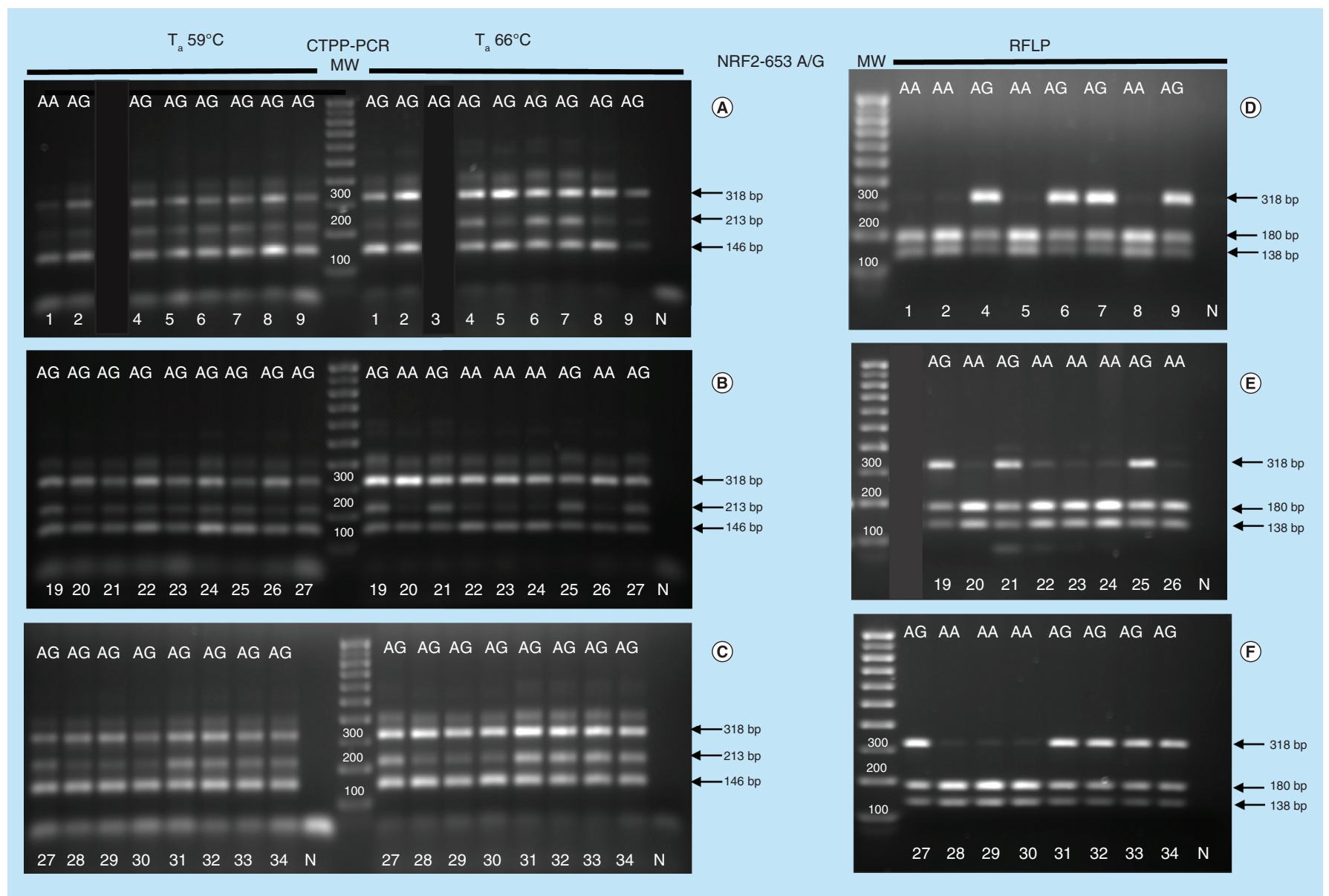

Figure 2. Comparison between CTPPCR and RFLP results for NRF2-653A/G. Confronting two-pair primers-polymerase chain reaction of NRF2 rs35652124 (-653 A/G) single nucleotide polymorphism performed at two different $\mathrm{T}_{\mathrm{a}}\left(59^{\circ}-66^{\circ} \mathrm{C}\right)$ using 1 unit/sample of Kapa Hot Start Taq polymerase (A-C). Restriction fragment length polymorphism analysis after amplicon digestion with BseRI (D-F). Sample ID and genotype are indicated by numbers and letters at the top and bottom of figures.

$\mathrm{N}$ : Negative control indicates DNA template omission in the polymerase chain reaction; MW: Molecular weights (100 bp up to $1000 \mathrm{bp}$ ). The black lanes are irrelevant samples for which the corresponding confronting two-pair primers-polymerase chain reaction was not reported.

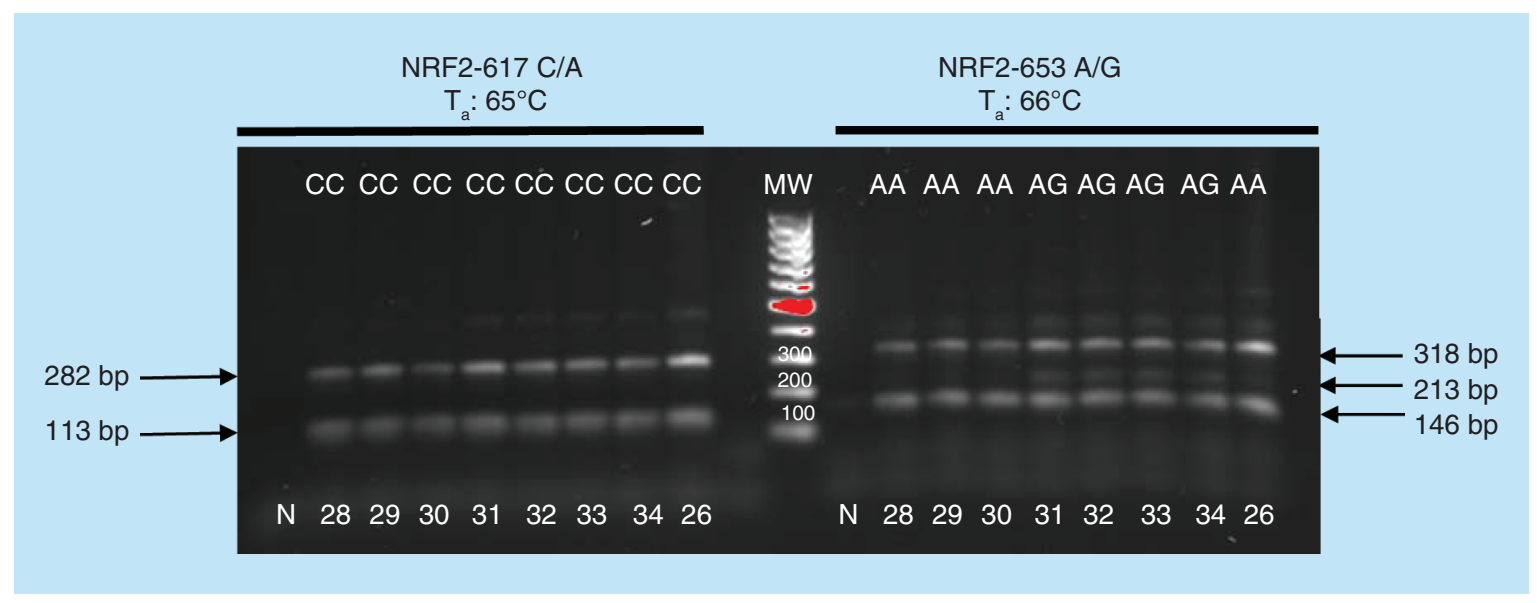

Figure 3. Confronting two-pair primers-polymerase chain reaction for NRF2 -617C/A and -653A/G was carried out at the indicated $\mathrm{T}_{\mathrm{a}}$ using $2.5 \mathrm{U} /$ sample of AmpliTaq Gold polymerase.

$\mathrm{N}$ : Negative control indicates DNA template omission. MW: Molecular weights (100 bp up to $1000 \mathrm{bp}$ ). 
Table 2. Effect of $\mathrm{T}_{\mathrm{a}}$ and Taq polymerase on the genotypic profile by confronting two-pair primers-polymerase chain reaction.

\begin{tabular}{|c|c|c|c|c|}
\hline \multirow[t]{3}{*}{ Subject ID } & \multicolumn{2}{|c|}{ NRF2 -617C/A } & \multicolumn{2}{|c|}{ NRF2 -653A/G } \\
\hline & \multicolumn{2}{|c|}{ Taq KAPA Biosystems } & \multicolumn{2}{|c|}{ Taq KAPA Biosystems } \\
\hline & $\mathrm{T}_{\mathrm{a}} 58^{\circ} \mathrm{C}$ & $\mathrm{T}_{\mathrm{a}} 65^{\circ} \mathrm{C}$ & $\mathrm{T}_{\mathrm{a}} 59^{\circ} \mathrm{C}$ & $\mathrm{T}_{\mathrm{a}} 66^{\circ} \mathrm{C}$ \\
\hline$\# 28$ & $\mathrm{CC}$ & CA & AG & AG \\
\hline$\# 29$ & $\mathrm{CC}$ & CA & AG & AG \\
\hline \#31 & $\mathrm{CC}$ & CA & AG & AG \\
\hline \multirow[t]{3}{*}{ \#34 } & $\mathrm{CC}$ & $\mathrm{CC}$ & AG & AG \\
\hline & \multicolumn{2}{|c|}{$\mathrm{T}_{\mathrm{a}} 65^{\circ} \mathrm{C}$} & \multicolumn{2}{|c|}{$\mathrm{T}_{\mathrm{a}} 66^{\circ} \mathrm{C}$} \\
\hline & TAQ Applied Biosystems & Taq KAPA Biosystems & TAQ Applied Biosystems & Taq KAPA Biosystems \\
\hline \#26 & CC & $\mathrm{CC}$ & AA & AA \\
\hline$\# 28$ & $\mathrm{CC}$ & CA & AA & AG \\
\hline \#29 & $\mathrm{CC}$ & CA & AA & AG \\
\hline \#30 & $\mathrm{CC}$ & CC & AA & AG \\
\hline \#31 & $\mathrm{CC}$ & CA & AG & AG \\
\hline \#32 & $\mathrm{CC}$ & $\mathrm{CC}$ & AG & AG \\
\hline \#33 & $\mathrm{CC}$ & CC & AG & AG \\
\hline \#34 & $\mathrm{CC}$ & $\mathrm{CC}$ & AG & AG \\
\hline
\end{tabular}

by $20 \mathrm{~min}$ at $80^{\circ} \mathrm{C}$ for enzyme inactivation. The restriction enzymes were a kind gift from EMBL. The predicted products obtained by RFLP have been worked-out and verified using the following bioinformatics simulators: www.bioinformatics.org/sms2/rest_digest.html and www.restrictionmapper.org/ and are shown in Table 1B.

\section{Results}

NRF2 -617C/A and NRF2-653 A/G SNP were characterized in 24 individuals by initially using already optimized experimental conditions [19,23]. The most critical parameter of CTPP-PCR is the competition of the primers for the target DNA. Since the annealing temperature $\left(T_{a}\right)$ regulates primer binding to complementary DNA, we performed PCR at two alternative $T_{a}$ to identify conditions which minimize primer competition. The results of the polymorphism analysis of NRF2 -617 C/A and -653 A/G SNPs relative to the 24 individual samples are shown in Figures 1 and 2. For $-617 \mathrm{C} / \mathrm{A}, \mathrm{PCR}$ products were in general better distinguishable when the highest $\mathrm{T}_{\mathrm{a}}\left(65^{\circ} \mathrm{C}\right)$ was used. For instance, the heterozygous genotype of sample $\# 6$ was visible when the highest $\mathrm{T}_{\mathrm{a}}\left(65^{\circ} \mathrm{C}\right)$ was used but was undetectable when processed at the lowest $\mathrm{T}_{\mathrm{a}}\left(58^{\circ} \mathrm{C}\right.$; Figure $\left.1 \mathrm{~A}\right)$. Also the genotype of sample \#24, \#25 obtained by CTPP-PCR (Figure 1B) was uncertain due to the presence of an intermediate faint band. The results could be confirmed and validated only by comparison with RFLP digestion patterns (Figure 1 A, B, C vs D, E, F). Looking at CTPP-PCR results, subject \#28 and \#29 (Figure 1C) could be misinterpreted as heterozygous instead of being homozygous, as shown in Figure 1F. In general, for several samples, the genotypes obtained by CTPP-PCR using the two different temperatures were not coincident.

Similarly, when the -653 C/A SNP was analyzed by CTPP-PCR, evident discrepancies in the genotyping results obtained at the two different $\mathrm{T}_{\mathrm{a}}$ were observed (Figure 2). For instance, it was impossible to draw sure conclusions

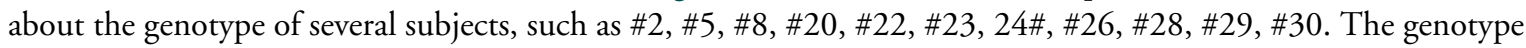
validation by RFLP analysis (Figure 2D, E, F) confirmed the homozygous wild-type genotypes of all those samples.

The sensitivity of the methodology to experimental factors was further challenged by substituting the polymerase in the reaction (Figure 3). Again, the results did not correspond to the previous ones obtained by using a Taq polymerase from another commercial vendor (Table 2). In these conditions, it became impossible to assess the overall population distribution of the alleles corresponding to the $-617 \mathrm{C} / \mathrm{A}$ and $-653 \mathrm{~A} / \mathrm{G}$ SNPs unless we could confirm the validity of results by RFLP.

\section{Discussion}

We applied CTPP-PCR to detect two polymorphisms located in the promoter of NRF2 gene and this could be informative for epidemiologic studies on occupational and environmental health. The initial aim of this work was to validate a faster, simpler and cost-effective alternative to the conventional two-step PCR-RFLP for SNP 
Table 3. Comparison of time and cost between confronting two-pair primers-polymerase chain reaction and polymerase chain reaction-restriction fragment length polymorphism.

\begin{tabular}{|c|c|c|c|c|}
\hline \multirow[t]{2}{*}{ Item } & \multicolumn{2}{|c|}{ Cost } & \multicolumn{2}{|c|}{ Time } \\
\hline & CTPP-PCR & PCR-RFLP & CTPP-PCR & PCR-RFLP \\
\hline Primers & $46.50 €$ & $23.25 €$ & $3 \mathrm{~h}$ & $3 \mathrm{~h}$ \\
\hline Shipping & $6.50 €$ & $6.50 €$ & - & - \\
\hline Taq polymerase $500 \mathrm{U}$ & $228.00 €$ & $114.00 €$ & - & - \\
\hline $\begin{array}{l}\text { RFLP enzyme } N g o M I V \\
(10,000 \mathrm{U} / \mathrm{ml})\end{array}$ & $0.00 €$ & $55.00 €$ & 0 & $2 \mathrm{~h}$ \\
\hline RFLP enzyme BseRI $(5000 \mathrm{U} / \mathrm{ml})$ & $0.00 €$ & $60.00 €$ & 0 & $2 \mathrm{~h}$ \\
\hline $\begin{array}{l}\text { Sample separation on agarose } \\
\text { gel }\end{array}$ & $43.50 €(10 \mathrm{~g})$ & $87.00 €(20 \mathrm{~g})$ & $3 \mathrm{~h}$ (one gel for PCR) & $\begin{array}{l}6 \mathrm{~h} \text { (two gels for PCR and } \\
\text { digestion) }\end{array}$ \\
\hline $0,2 \mathrm{ml}$ tubes & $8.00 €$ & $16.00 €$ & - & - \\
\hline $1 \mathrm{ml}$ tubes & $5.00 €$ & $10.00 €$ & - & - \\
\hline TBE buffer & $30.60 €$ & $61.20 €$ & - & - \\
\hline Total & $368.10 €$ & $432.95 €$ & $6 \mathrm{~h}$ & $13 \mathrm{~h}$ \\
\hline
\end{tabular}

NgoMIV and BseRI restriction enzymes have been used for PCR-RFLP of -617C/A and -653A/G NRF2 polymorphism in [14].

This table does not consider the costs and time necessary for the control experiments to validate the data produced by CTPP-PCR.

CTPP: Confronting two-pair primer; PCR: Polymerase chain reaction; RFLP: Restriction fragment length polymorphism.

evaluation (Table 3). However, our attempt to replicate the published protocol described in other papers [19,22,23] shows that CTPP-PCR produced rather ambiguous and even contradictory results that had to be validated by employing an orthogonal genotyping technique. Such results confirmed that CTPP-PCR is a technique extremely sensitive to experimental conditions, the most critical of which is the design of the four primers to obtain the most possible similar $T_{m}$ values and avoiding primer pairs competition for the DNA template during PCR [13,24]. However, variations of $T_{a}$ value and polymerase type also resulted in differing results, underlining that CTPP-PCR requires long optimization and control procedures for each single SNP. Clearly, such procedures would nullify all the potential advantages of CTPP-PCR in terms of costs and time (Table 3) with respect to PCR-RFLP [6-9,19,22].

Since in our experiments CTPP-PCR was performed according to published methods, with the same described primers and at the same experimental conditions [19,23], we cannot exclude inconsistencies in previous publications because no image of genotyping was shown in the original papers [19,22]. This condition prevents assessing if ambiguous results, such as the ubiquitous and low-intensity presence of the F2-R2 -653A/G SNP amplicon, were generated also in those experiments. In any case, diagnostic genotyping should be objective and not subjectively interpreted by researchers according to the varying intensity of PCR products. Therefore, we would suggest considering with caution CTPP-PCR for SNP analysis, limiting its use to those cases in which no reliable restriction enzyme would be available for PCR-RFLP. As a control step, we recommend to sequence the obtained fragments. More generally, we plead for the publication of reports with complete experimental dataset for comprehensive evaluation of their quality.

\section{Conclusion}

CTPP-PCR is a potentially fast, simple and cost-saving methodology useful in detecting gene polymorphisms by using two primer pairs. However, as shown here, ambiguous genotyping might occur regardless of the optimization attempts. This strongly depends on experimental conditions, primer design and specificity, which may result in unreliable classification of genotypes, particularly for heterozygosis. The identification of the appropriate experimental conditions for several gene polymorphisms requires time, work and financial resources. Since biomedical research and diagnostics must provide high data reproducibility [25], we strongly advise accurate protocol optimization and result validation prior to use CTPP-PCR for massive genetic screening.

\section{Future perspective}

Single nucleotide substitutions are the most common type of genetic variations in humans. These are known as biomarkers of susceptibility toward the exposure to xenobiotics and are of great relevance for public health. In the occupational setting, the association between exposure to xenobiotics and variable functionality of SNPs involved in a specific metabolism is extremely important to identify individual susceptibilities and improve worker health 
and safety. Besides methods such as PCR-RFLP, CTPP-PCR, PCR-ARMS (Amplification Refractory Mutation System) and mass spectrometry, further alternative technologies have been developed, in other words, Taqman assay, High-Resolution Melting and different types of mini-sequencing. It seems that the trend in the development of genotyping is moving toward multiplexing strategies and miniaturization [26] for assessing a large number of SNPs simultaneously [27]. In the field of occupational medicine, the progressive availability of data concerning the allele frequencies of the polymorphisms involved in detoxification would contribute to identify the most predictive tests, and consequently to reduce less informative genetic tests.

\section{Executive summary}

- Confronting two-pair primers-polymerase chain reaction is a potentially fast, simple and cost-saving method to detect gene polymorphism biomarkers based on the use of two primer pairs.

- When the technique was applied for the genotyping of two single nucleotide polymorphisms of NRF2 gene produced ambiguous results.

- Validation of confronting two-pair primers-polymerase chain reaction with an orthogonal technique is mandatory to ensure reliable results for gene polymorphism biomarkers.

Supplementary data

To view the supplementary data that accompany this paper please visit the journal website at: www.futuremedicine.com/doi/full/ 10.2217/fsoa-2018-0075

Financial \& competing interests disclosure

The authors have no relevant affiliations or financial involvement with any organization or entity with a financial interest in or financial conflict with the subject matter or materials discussed in the manuscript. This includes employment, consultancies, honoraria, stock ownership or options, expert testimony, grants or patents received or pending, or royalties.

No writing assistance was utilized in the production of this manuscript.

Acknowledgments

The authors are grateful to JD Lewis (European Molecular Biology Laboratory), A Mansi, E Paba, A Proietto, I Amori, A Marcelloni, A Chiominto (INAIL) for providing access to laboratory reagents and M Passaro (INAIL fellowship holder) for the technical assistance.

Ethical conduct of research

All procedures performed in this study involving human participants (Declaration of Helsinki) were in accordance with the ethical standards of our institutional committee and in accordance with the local ethics committee.

\section{Author contributions}

With regard to the author contribution all authors participated in drafting the manuscript. PC conceived the study, performed the $P C R$, analysed data and wrote the manuscript. AdM analysed and interpreted the data and critically reviewed the manuscript. RS provided the blood samples for the analysis and contributed to the discussion on NRF2 polymorphism relevance in the occupational exposures.

\section{Open access}

This work is licensed under the Creative Commons Attribution 4.0 License. To view a copy of this license, visit http://creativecomm ons.org/licenses/by/4.0/

\section{References}

Papers of special note have been highlighted as: $\bullet$ of interest; $\bullet \bullet$ of considerable interest

1. Ladeira C, Viegas S. Human Biomonitoring - an overview on biomarkers and their application in occupational and environmental health. Biomonitoring 3, 15-24 (2016).

2. Christiani DC, Mehta AJ, Yu CL. Genetic susceptibility to occupational exposures. Occup. Environ. Med. 65, 430-436 (2008).

3. Botstein D, White R, Skolnick M, Davis RW. Construction of a genetic linkage map in man using restriction fragment length polymorphisms. Am. J. Hum. Genet. 32, 314-331 (1980). 
4. Drum B, Cichna-Mark M. High resolution melting (HRM) analysis of DNA-its role and potential in food analysis. Food Chem. 158, 245-254 (2014).

5. Latini FR, Castilho LM. An overview of the use of SNaPshot for predicting blood group antigens Immunohematology. 31, 53-57 (2015).

6. Hamajima N, Saito T, Matsuo K, Kozaki K, Takahashi T, Tajima K. Polymerase chain reaction with confronting two-pair primers for polymorphism genotyping. Jpn J. Cancer Res. 91, 865-868 (2000a).

- Describes the rationale followed to develop the confronting two-pair primer-polymerase chain reaction technology

7. Hamajima N. PCR-CTPP: a new genotyping technique in the era of genetic epidemiology. Expert Rev. Mol. Diagn. 1, 119-123 (2001).

8. Maruyama C, Suemizu H, Tamamushi S Kimoto, Tamaoki N, Ohnishi Y. Genotyping the mouse severe combined immunodeficiency mutation using the polymerase chain reaction with confronting two-pair primers (PCR-CTPP). Exp. Anim. 51, 391-393 (2002).

9. Tamakoshi A, Hamajima N, Kawase H et al. Duplex polymerase chain reaction with confronting two-pair primers (PCR-CTPP) for genotyping alcohol dehydrogenase beta subunit (ADH2) and aldehyde dehydrogenase 2 (ALDH2). Alcohol Alcohol. 5, 407-410 (2003).

10. Tharinjaroen CS, Intorasoot S, Anukool U et al. Novel targeting of the lepB gene using PCR with confronting two-pair primers for simultaneous detection of Mycobacterium tuberculosis complex and Mycobacterium bovis. J. Med. Microbiol. 65, 36-43 (2016).

11. Hamajima N, Saito T, Matsuo K, Tajima K. Competitive amplification and unspecific amplification in polymerase chain reaction with confronting two-pair primers. J. Mol. Diagn. 4, 103-107 (2002b).

-• Highlights the strategies to avoid unspecific amplification in genotyping using the confronting two-pair primer-polymerase chain reaction methodology.

12. Yin G, Mitsuda Y, Ezaki T, Hamajima N. A new PCR method: one primer amplification of PCR-CTPP products. Mol. Biotechnol. 52, 180-183 (2012).

13. Chang WH, Chuang LY, Cheng YH et al. Prim-SNPing: a primer designer for cost-effective SNP genotyping. Biotechniques 4, 421-431 (2009).

14. Cho HY, Marzec J, Kleeberger SR. Functional polymorphisms in NRF2: implications for human disease. Free Radic. Biol. Med. 88, 362-372 (2015).

15. Hoshino T, Tabuchi K, Nishimura B et al. Protective role of NRF2 in age-related hearing loss and gentamicin ototoxicity. Biochem. Biophys. Res. Comm. 415, 94-98 (2011).

16. Honkura $\mathrm{Y}$, Matsuo $\mathrm{S}$, Murakami $\mathrm{M}$ et al. NRF2 is a key target for prevention of noise-induced hearing loss by reducing oxidative damage of cochlea. Sci. Rep. 6, 19329 (2016).

-. In this paper the authors find association between a polymorphism of NRF2 gene and the increase of susceptibility to noise-induced hearing loss in the occupational setting.

17. Song P, Li K, Liu L et al. Genetic polymorphism of the NRF2 promoter region is associated with vitiligo risk in Han Chinese populations. J. Cell Mol. Med. 20, 1840-1850 (2016).

18. Guan CP, Zhou MN, Xu AE et al. The susceptibility to vitiligo is associated with NF-E2-related factor2 (NRF2) gene polymorphisms: a study on Chinese Han population. Exp. Dermatol. 17, 1059-1062; 8 (2008).

19. Shimoyama Y, Mitsuda Y, Tsuruta Y, Hamajima N, Niwa T. Polymorphism of NRF2, an antioxidative gene, is associated with blood pressure and cardiovascular mortality in hemodialysis patients. Int. J. Med. Sci. 11, 726-731 (2014a).

20. Marzec JM, Christie JD, Reddy SP et al. Functional polymorphisms in the transcription factor NRF2 in humans increase the risk of acute lung injury. Faseb J. 21, 2237-2246 (2007).

21. Chiarella P, Carbonari D, Capone P et al. Susceptibility biomarker detection in urine exfoliate DNA. Biomark. Med. 11, 957-966 (2017).

22. Shimoyama Y, Mitsuda Y, Hamajima N, Niwa T. Polymorphisms of NRF2, an antioxidative gene, are associated with blood pressure in Japanese. Nagoya J. Med. Sci. 76, 113-120 (2014b).

23. Al Azhary NM, Kamel MM, Ismail YM, Mahmoud AA, Radwan EM. The role of genetic polymorphisms in NRF2 and P73 in Egyptian women with breast cancer. Asian Pac. J. Cancer Prev. 17, 4945-4949 (2016).

24. Yang $\mathrm{CH}$, Cheng YH, Chuang LY, Chang HW. Confronting two-pair primer design for enzyme-free SNP genotyping based on a genetic algorithm. BMC Bioinformatics 11, 509 (2010).

25. Nath SB, Marcus SC, Druss BG. Retractions in the research literature: misconduct or mistakes? Med. J. Aust. 185, 152-154 (2006).

-. Discusses the mistakes and omissions made in scientific publications, highlighting the necessity of data reproducibility.

26. Landegren U, Nilsson M, Kwok PY. Reading bits of genetic information: methods for single-nucleotide polymorphism analysis. Genome Res. 8, 769-776 (1998).

27. Shen W, Tian Y, Ran T, Gao Z. Genotyping and quantification techniques for single-nucleotide polymorphisms. Trends Analyt. Chem. 69, 1-13 (2015). 
